\title{
Frequencies of neuronal autoantibodies in healthy controls
}

\author{
Estimation of disease specificity
}

\section{OPEN}

Katharina Lang

Harald Prüss, MD

Correspondence to

Dr. Prüss:

harald.pruess@charite.de
Supplemental data at Neurology.org/nn

\section{ABSTRACT}

Objective: To provide an extensive overview on the prevalence of antibodies against neuronal surfaces (neuronal surface antibody [NSAb]) in healthy participants and disease controls.

Methods: We searched the PubMed database (1974 to October 2016) for studies that analyzed frequencies of 22 different NSAbs in serum or CSF and included controls. Antibody prevalence was calculated for patients with NSAb-mediated disease and controls, including healthy participants, and those with neurologic and nonneurologic diseases. Different assays for antibody detection were compared.

Results: In 309 articles, 743,299 antibody tests for 22 NSAbs were performed, including 30,485 tests for 19 NSAbs in healthy controls (HCs). Of these, 26,423 (86.7\%) were tested with current standard methods, usually cell-based assays. Prevalence was very low in $\mathrm{HCs}$ (mean $0.23 \%$, absent for 9/19 antibodies), and test numbers ranged from 21 to 3,065 per antibody. One study reported $>1,000$ healthy participants, and the others contained $21-274$ samples. CSF samples were virtually not available from HCs. NSAb prevalence was considerably higher (1.5\%) in 69,850 disease controls, i.e., patients not initially suspected to have NSAb-mediated diseases. Antibody determination in controls using nonstandard assays (such as ELISA) resulted in $6 \%$ positivity.

Conclusions: NSAbs are rarely found in healthy participants, particularly with standard detection methods, suggesting high disease specificity and supporting their diagnostic usefulness. Conversely, positive titers in atypical patients might point to the still expanding phenotypic spectrum. Future studies should include more CSF samples, data from HCs, and experimental evidence for antibody pathogenicity. Neurol Neuroimmunol Neuroinflamm 2017;4:e386; doi: 10.1212/NXI.0000000000000386

\section{GLOSSARY}

AMPAR1/2, AMPAR3 = alpha-amino-3-hydroxy-5-methyl-4-isoxazolepropionic acid receptor subunits 1/2 and 3; AQP4 = aquaporin-4; Caspr2 = contactin-associated protein-like 2; $\mathbf{C B A}=$ cell-based assay; $\mathbf{D 2 R}=$ dopamine-2 receptor; $\mathbf{D N E R}=$ delta/notch-like epidermal growth factor-related receptor; DPPX = dipeptidyl-peptidase-like protein 6; FACS = fluorescence-activated cell sorting; GABAaR and GABAbR = gamma-aminobutyric acid-A and -B receptor; $\mathbf{G l y R}=$ glycine receptor; HC = healthy control; IgLON5 = cell adhesion molecule IgLON family member 5; IHC = immunohohstochemistry; Lgi1 = leucine-rich glioma-inactivated protein $1 ;$ mGluR5 = metabotropic glutamate receptor 5 ; MOG = myelin oligodendrocyte glycoprotein; $\mathbf{n A C h R}(\mathbf{m}), \mathbf{n A C h R}(\mathbf{g})=$ nicotinic acetylcholine receptor of muscle $(\mathrm{m})$ and ganglionic $(\mathrm{g})$ type; NMDAR/NR1, NMDAR/NR2 $=\mathrm{N}$-methyl-D-aspartate-receptor subunits NR1 or NR2; NSA $\mathbf{b}=$ neuronal surface antibody; PRG5 = plasticity-related gene 5; $\mathbf{R I A}=$ radioimmunoassay; $\mathbf{V G K C}=$ voltage-gated potassium channel; $\mathbf{W B}=$ Western blot.

Over the past years, Neurology and Psychiatry have witnessed a breathtaking development in the field of neuronal surface antibody (NSAb)-mediated diseases. Since the description of an encephalitis associated with antibodies against the NMDA receptor (NMDAR) in 2007, ${ }^{1}$ more than 15 new NSAbs have been identified as the pathogenic agents in diverse neuropsychiatric syndromes. ${ }^{2-7}$

The relative novelty of the antibodies and the associated, still expanding clinical pictures occasionally cause a dilemma. The presence of an atypical neuropsychiatric syndrome together with positive NSAb titers not always allows the conclusion that the antibody is causing the disease. The antibody might indeed be causative for a broader phenotype than initially appreciated or merely represent an

From the German Center for Neurodegenerative Diseases (DZNE) Berlin (K.L., H.P.); and Department of Neurology and Experimental Neurology (K.L., H.P.), Charité-Universitätsmedizin Berlin, Germany.

Funding information and disclosures are provided at the end of the article. Go to Neurology.org/nn for full disclosure forms. The Article Processing Charge was funded by German Center for Neurodegenerative Diseases (DZNE) Berlin.

This is an open access article distributed under the terms of the Creative Commons Attribution-NonCommercial-NoDerivatives License 4.0 (CC BY-NC-ND), which permits downloading and sharing the work provided it is properly cited. The work cannot be changed in any way or used commercially without permission from the journal. 
unspecific finding or a false-positive test result. In other words, when a test for NSAbs in clinical practice returns positive in blood or CSF, how likely is an underlying antibody-mediated disease?

This question of NSAb specificity is highly relevant since positive test results are the common rationale for an (often aggressive) immunotherapy. To date, there is no systematic literature review analyzing the frequency of NSAbs in control populations. In particular, knowledge of the frequency in healthy participants would be a valuable source to determine disease specificity of autoantibodies, as theyby definition-lack symptoms of an antibodymediated disease. The purpose of this study is to provide an extensive overview on NSAb prevalence in healthy and disease controls, evaluating data from more than 700,000 antibody tests for the 22 most relevant NSAbs, using human serum or CSF (figure 1 and table e-1 at Neurology.org/nn).

METHODS Literature research. This review article comprehensively analyzed the PubMed database literature from 1974 to October 2016 using the search terms "antibody" and "encephalitis" together with the antigens: acetylcholine receptor, nAChR, AMPA receptor, AQP4, aquaporin-4, caspr2, d2 receptor, dopamine-2 receptor, DNER, DPPX, GABAa receptor, GABAb receptor, glycine receptor, IgLON5, lgi1, metabotropic glutamate receptor 5, mGluR5, MOG, neurofascin, NMDAR, and VGKC.

Selection criteria. Articles were considered that tested for $\geq 1$ of the $22 \mathrm{IgG}$ antibodies and included (1) serum or CSF samples of a control population in addition to the disease group and (2) provided the exact number of tested control samples. For NSAbs with only few publications (D2R, DNER, DPPX, GlyR, IgLON5, mGluR5, PRG5, and neurexin-3a), we considered all published articles.

Analysis. The cohorts were categorized into 3 groups—based on the classification provided in the respective articles:

Figure 1 Number of individual antibody tests reviewed in the present analysis

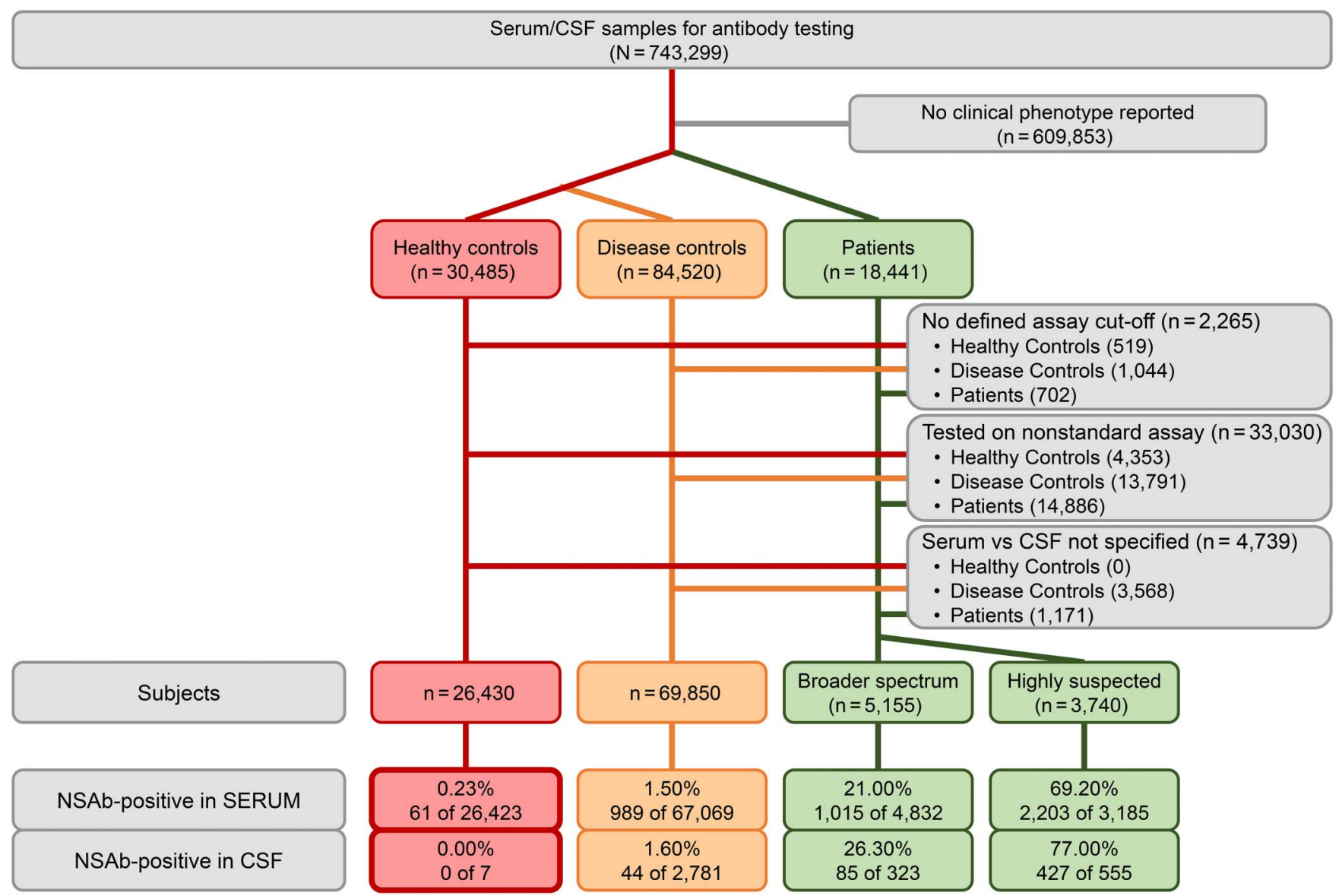

Focusing on the frequency of neuronal surface antibody (NSAb) in healthy controls, almost 26,500 individual antibody tests were performed. Of these, NSAb-positive samples are very rare $(0.23 \%)$, indicating high disease specificity and supporting their pathogenic role and diagnostic usefulness in clinical routine. The majority of the reviewed 743,299 antibody tests for 22 NSAbs had to be excluded from analysis, as the respective articles did not report on the clinical phenotype of their participants, used assays without defined cutoffs or nonstandard assays, or did not specify whether the test was performed on either serum or CSF. 
1. Patients, defined by having symptoms for which NSAbs are accepted to be specific, such as anti-NMDA receptor encephalitis; this group was sub-categorized into 2 cohorts, i.e., those with a highly suspicious clinical picture (fulfilling accepted diagnostic criteria, if available) and those with a broader clinical spectrum (table e-2).

2. Healthy participants, defined by exclusion of disease, usually via questionnaires. In studies often referred to as "healthy," "normal," or "blood donors."

3. Disease controls, containing multiple CNS disorders (table e-1), further subdivided into

a. Inflammatory other neurologic diseases (OND): other neurologic diseases with inflammation, such as demyelinating disorders and brain infections,

b. Noninflammatory OND: other noninflammatory neurologic diseases, such as degenerative disorders, neurologic tumors, and epilepsy,

c. Inflammatory other diseases (OD): other nonneurological diseases with inflammation, such as rheumatoid diseases and systemic infections,

d. Noninflammatory OD: other nonneurological diseases without inflammation, such as malignancies,

e. Psychiatric disorders.
RESULTS Using the search strategy, more than 1,000 articles on novel NSAbs were screened. From these, 309 articles included NSAb testing in healthy and disease controls (table 1). The publication dates ranged from 1974 for $\mathrm{nAChR}^{8}$ to October 2016.

In total, 30,485 serum and CSF samples of healthy controls (HCs), 84,520 of disease controls, and 18,441 samples of patients were tested for 1 of the 22 antibodies. A total of 609,853 tests were derived from patients for whom no clinical information has been provided (figure 1). The numbers include serum samples, CSF samples, and samples that are unspecified for serum or CSF by the authors.

From all HC samples, $99.9 \%$ were serum specimen. Most samples of HCs were tested for MOG antibodies $(\mathrm{n}=3,658)$, including $\mathrm{n}=28$ CSF samples, least for neurexin-3a antibodies $(n=21)$ and none for igLON5 (for details, see table 1).

Regarding disease controls, $92 \%(\mathrm{n}=77,775)$ of all tests included serum samples, and $4 \%$ were CSF ( $\mathrm{n}$

Table 1 Numbers of included articles and tested samples per antibody

\begin{tabular}{|c|c|c|c|c|c|c|c|c|c|c|}
\hline \multirow[b]{2}{*}{ Antigen } & \multirow[b]{2}{*}{ Articles } & \multicolumn{3}{|l|}{ HCs } & \multicolumn{3}{|c|}{ Disease controls } & \multicolumn{3}{|c|}{ Patients } \\
\hline & & Serum & CSF & NS & Serum & CSF & NS & Serum & CSF & NS \\
\hline AMPAR1/2 & 28 & 2,172 & - & - & 5,245 & 113 & 252 & 22 & 22 & 129 \\
\hline AMPAR3 & 9 & 399 & - & - & 1,149 & - & - & 123 & - & - \\
\hline AQP4 & 82 & 3,065 & - & - & 8,864 & 489 & 48 & 4.988 & 135 & 61 \\
\hline D2R & 13 & 232 & - & - & 868 & 13 & 14 & 81 & - & - \\
\hline DNER & 6 & 1,776 & - & - & 3,550 & - & - & 55 & 2 & - \\
\hline DPPX & 12 & 1,753 & - & - & 3,465 & 12 & 464 & 118 & 3 & - \\
\hline GABAaR & 12 & 285 & - & - & 1,660 & 203 & 589 & 276 & 160 & 57 \\
\hline GABAbR & 23 & 1,836 & - & - & 4,768 & 153 & 141 & 91 & 15 & - \\
\hline GlyR & 23 & 1,960 & - & - & 5,688 & 135 & 368 & 359 & 86 & 45 \\
\hline IgLON5 & 3 & - & - & - & - & - & 298 & 10 & 10 & - \\
\hline mGluR5 & 10 & 1,703 & - & - & 3,460 & 1 & 128 & 2 & 1 & - \\
\hline MOG & 52 & 3,630 & 28 & - & 4,934 & 328 & 50 & 4.407 & 643 & 109 \\
\hline $\mathrm{nAChR}, \mathrm{m}$ & 25 & 877 & - & - & 3,687 & 10 & - & 819 & - & - \\
\hline nAChR, g & 15 & 1,073 & - & - & 2,227 & 10 & - & 306 & - & - \\
\hline Neurexin-3a & 1 & 21 & - & - & - & - & 179 & 5 & 5 & - \\
\hline Neurofascin & 12 & 433 & - & - & 905 & - & - & 2.114 & 2 & - \\
\hline NMDAR/NR1 & 64 & 3,204 & 7 & - & 8,249 & 1,564 & 539 & 518 & 336 & 334 \\
\hline NMDAR/NR2 & 11 & 124 & - & & 905 & 86 & 133 & 259 & 53 & - \\
\hline PRG5 & 1 & 97 & - & - & 206 & - & - & 49 & 1 & - \\
\hline VGKC & 44 & 1,366 & - & - & 5,034 & 226 & 115 & 372 & 29 & 180 \\
\hline Caspr2 & 37 & 2,238 & - & - & 6,640 & 28 & 14 & 405 & - & 147 \\
\hline Lgi1 & 36 & 2,206 & - & - & 6,271 & 28 & 14 & 344 & - & 153 \\
\hline Total & 309 & 30,450 & 35 & - & 77,775 & 3,399 & 3,346 & 15,723 & 1,503 & 1,215 \\
\hline
\end{tabular}

Abbreviations: $\mathrm{HC}=$ healthy control; NMDAR $=$ NMDA receptor; NS $=$ not specified.

The numbers of reported neuronal surface antibody tests vary widely depending on the specific antibody, just as the numbers of publications. Of 30,485 available samples from HCs, only 35 were CSF specimens. When a publication contained tests for different antibodies in the same subject, they were counted here as individual tests. 
$=3,399)$ or remained unspecified for either serum or CSF ( $\mathrm{n}=3,346)$. The largest number of disease controls was tested ( $\mathrm{n}=10,352)$ for NMDAR/ NR1 antibodies, and the smallest number with $\mathrm{n}=$ 179 samples for neurexin-3a (table 1).

Among tested samples categorized as "patients," $85 \%(\mathrm{n}=15,723)$ were serum samples, only $8.2 \%$ $(\mathrm{n}=1,503) \mathrm{CSF}$, and 6.6\% $(\mathrm{n}=1,215)$ were not specified. The number of tested patient samples ranged from $\mathrm{n}=3$ for mGluR5 to $\mathrm{n}=5,184$ for AQP4 antibodies (table 1).

Various antibody assays. A wide variety of laboratory methods have been used to detect NSAbs across studies, in particular ELISA, Western blots (WBs), radioimmunoassays (RIAs), fluorescence immunoprecipitation assays, immunohistochemistry on sections of rodent brain, fluorescence-activated cell sorting (FACS), and cell-based assays (CBA) with visual evaluation of immunofluorescence-tagged secondary antibodies. Earlier descriptions of antibodies showed a broader repertoire of test methods, possibly related to a lack of standardization. By contrast, testing for more recent NSAbs, such as IgLON5, mGluR5, neurexin-3a, and PRG5, was generally restricted to CBAs (table 2).

In fact, the CBA has become the standard method for most NSAbs and is widely available in commercial laboratories. ${ }^{9,10} \mathrm{CBAs}$, comprising assays with fixed as well as live cells, turned out to have superior sensitivity for detection of NSAbs since they are specific for 1 antigen and its actual conformation is preserved. ${ }^{11}$ For MOG antibodies, for instance, the binding to nonconformational MOG, as in WB or ELISA, is not specific for demyelinating diseases and does not correlate with the binding to conformational MOG in CBA or FACS on cells transfected with human MOG. ${ }^{12}$ Furthermore, control groups may interfere

\begin{tabular}{|c|c|c|c|c|c|c|}
\hline \multirow[b]{3}{*}{ Antigen } & \multicolumn{6}{|c|}{$\begin{array}{l}\text { Comparison of the diagnostic standard method and other methods for testing healthy control and } \\
\text { disease control samples }\end{array}$} \\
\hline & \multicolumn{3}{|c|}{ Standard method } & \multicolumn{3}{|l|}{ Other methods } \\
\hline & & Controls (n) & Positive (\%) & & Controls (n) & Positive (\%) \\
\hline AMPAR1/2 & CBA & 7,422 & $6(0.1)$ & IHC, WB & 156 & $18(11.5)$ \\
\hline AMPAR3 & & 239 & 0 & ELISA, IHC, WB & 964 & 118 (12.2) \\
\hline AQP4 & & 7,692 & 103 (1.3) & ELISA, FACS, FIPA, IHC, RIA, WB & 7,346 & 134 (1.8) \\
\hline D2R & & 130 & 0 & FACS, IHC, RIA & 507 & $25(4.9)$ \\
\hline DNER & & 5,326 & $2(0.0)$ & IHC & 207 & 0 \\
\hline DPPX & & 5,694 & $4(0.1)$ & IHC, WB & 143 & 0 \\
\hline GABAaR & & 2,687 & $34(1.3)$ & IHC, WB & 76 & 21 (27.6) \\
\hline GABAbR & & 6,653 & $15(0.2)$ & ELISA, IHC & 294 & $27(9.2)$ \\
\hline GlyR & & 8,151 & 109 (1.3) & ND & & \\
\hline IgLON5 & & 298 & $1(0.3)$ & ND & & \\
\hline mGluR5 & & 5,292 & $2(0.0)$ & ND & & \\
\hline MOG & & 5,209 & $20(0.4)$ & ELISA, FACS, RIA, WB & 3,641 & $364(10.0)$ \\
\hline Neurexin-3a & & 200 & 0 & ND & & \\
\hline Neurofascin & & 398 & $4(1.0)$ & ELISA, FACS & 1,080 & $15(1.4)$ \\
\hline NMDAR/NR1 & & 13,136 & 140 (1.1) & ELISA, FIPA, IHC, WB & 1,197 & 45 (3.8) \\
\hline NMDAR/NR2 & & 104 & 0 & ELISA, IHC, WB & 1,144 & $199(17.4)$ \\
\hline PRG5 & & 303 & 0 & ND & & \\
\hline Caspr2 & & 8,799 & $122(1.4)$ & ELISA, FIPA, IHC & 239 & 0 \\
\hline Lgi1 & & 8,476 & 100 (1.2) & ELISA, IHC & 74 & $1(1.4)$ \\
\hline $\mathrm{nAChR}(\mathrm{m})$ & RIA & 4,288 & $73(1.7)$ & CBA, ELISA, Other & 259 & 31 (12.0) \\
\hline $\mathrm{nAChR}(\mathrm{g})$ & & 3,124 & $123(3.9)$ & LIPS & 186 & $9(4.8)$ \\
\hline VGKC & & 6,227 & $318(5.1)$ & CBA, IHC & 598 & $51(8.5)$ \\
\hline Total & & 99,848 & $1,176(1.18)$ & & 18,111 & $1,058(5.8)$ \\
\hline
\end{tabular}

Abbreviations: $\mathrm{CBA}=$ cell-based assay; FACS = fluorescence-activated cell sorting; FIPA = fluorescence immunoprecipitation assays; IHC = immunohistochemistry; LIPS = luciferase-immunoprecipitation assay; ND = not done; NMDAR = NMDA receptor; RIA = radioimmunoassay; WB = Western blot.

Different laboratory methods have been used to detect neuronal surface antibodies. Of these, CBA (and in few tests RIA) has become the standard method because of superior sensitivity and commercial acceptance and dissemination. 
with assay interpretation, such as in hypergammaglobulinemia or rheumatoid diseases ${ }^{13}$; they are therefore provided separately in detail (table e-1).

Therefore, throughout this review, we define the CBA as "standard method" for all NSAbs except for VGKC and nAChR antibodies, for which the standard method is the RIA (table 2). For AQP4, ELISA and FACS are still frequently used, ${ }^{13}$ but considered nonstandard and thus grouped together with higher seropositivity (2.4\%) compared with CBA (1.3\%). Although the detection of VGKC antibodies with RIA has currently been replaced by the CBA for the disease-specific target antigens Lgi1 and Caspr $2,{ }^{14}$ the still wide availability of testing prompted us to include VGKC complex antibodies (with and without Lgil/Caspr2 antibodies) to provide clinicians with antibody frequencies (table e-1).

Overall, 1.2\% of blood and CSF samples from controls (i.e., suspected of not having an antibodymediated disease) were positive with the standard method. By contrast, $5.8 \%$ of the control samples yielded a positive result if tested with nonstandard methods, suggesting a markedly higher rate of falsepositives (table 2).

All following analyses of the NSAbs prevalence will consider samples tested with the standard methods only. Samples tested with other methods (e.g., ELISA not providing a clear cutoff for positivity; figure 1) are categorized in table e-1.

NSAbs are very rare in healthy participants. Serum analyses revealed a low frequency of NSAbs in HCs, on average $0.23 \%(n=61)$ of 26,423 antibody tests (table e-3). In detail, $0 \%$ positivity was seen for 9 different antibodies including 8,822 tests, namely for AMPAR3, AQP4, DNER, GABAaR, GABAbR, mGluR5, nAChR (m), neurexin-3a, and PRG5. On average, 1,201 samples were tested per antibody. No tests on HCs were reported yet with CBA for D2R, IgLON5, and NMDAR/NR2 (tables e-1 and e-3).

For comparison, the frequency in disease controls was somewhat higher with $1.5 \%(\mathrm{n}=989)$ of 67,069 tests, depending on the clinical subgroup. NSAbs in the psychiatric cohort $(0.25 \%$ of 28,491$)$ were similarly common as in HCs. NSAbs occurred with increasing frequency in inflammatory OD $(0.34 \%$ of 888 tests), noninflammatory OND (1.76\% of $17,718)$, noninflammatory OD $(2.18 \%$ of 6,889$)$, and inflammatory OND $(3.46 \%$ of 13,083$)$ (table $\mathrm{e}-3)$. Noteworthy is the high prevalence in noninflammatory OD, which likely relates to underlying malignancies in $76.7 \%$ of NSAb-positive noninflammatory OD patients.

No positive antibodies in disease controls were seen for AMPAR3, D2R, NMDAR/NR2, and PRG5. By contrast, VGKC antibodies were frequently detected with a positivity rate of $6.1 \%$ in 4,220 samples. Samples from disease controls tested for IgLON5 and neurexin-3a were not specified for either serum or CSF and are therefore not listed in table e-3. One of 298 noninflammatory OND was positive for antibodies against IgLON5, but none of 179 disease controls for neurexin-3a antibodies (table e-1).

In contrast to healthy and disease controls, patients in which an NSAb-mediated disease was suspected on clinical grounds indeed had profoundly higher prevalences. NSAbs were detected in $21.0 \%$ of 4,832 samples in the group with less specific clinical symptoms, while patients with a highly suggestive clinical picture were NSAb-positive in $69.2 \%$ of 3,185 serum samples.

Limited data on antibody frequencies in CSF. Given the invasive nature of a lumbar puncture, almost no data are available on CSF antibodies in HCs. One study reported 7 samples acquired in the diagnostic workup of headache; all were negative for NMDAR/NR1 antibodies (table e-4). ${ }^{15}$ As also examined for headache, 1 of $28 \mathrm{HCs}$ was positive in CSF for MOG antibodies tested by ELISA. ${ }^{16}$

From disease controls 2,781 CSF samples have been tested with the standard method for 14 of 22 antibodies. Forty-four (1.6\%) positive samples were identified for AQP4, GlyR, NMDAR/NR1, and VGKC antibodies. From these, 35 belonged to the inflammatory OND cohort; 8.2\% (of 135 samples) were positive for GlyR, 5.3\% (of 19) for VGKC, $2.1 \%$ (of 468) for AQP4, and 1\% (of 1,551) positive for NMDAR/NR1 antibodies. No CSF was available for AMPAR3, DNER, neurofascin, NMDAR/NR2, and PRG5 (table e-4).

In contrast to healthy and disease controls, patients with suspected NSAb-mediated symptoms had indeed a higher prevalence of CSF antibodies. However, the prevalence of NSAbs largely depended on the cohort size and selection. The highest prevalence of $100 \%$ is reached in the smallest cohorts with an average of only 4.7 CSF samples per antibody; this includes antibodies against DNER, DPPX, GABAbR, neurexin-3a, neurofascin, and PRG5. Altogether, patients with a highly suggestive clinical picture were CSF NSAb-positive in 76.9\% (of 555 samples) and patients with a less distinctive clinical picture still in $26.3 \%$ (of 323 samples) (table e-4).

Most studies contained small numbers of controls. It became obvious from the literature research on NSAbs that most studies tested only small numbers of control samples (figure e-1). In fact, only 1 study included a large number of HCs and might thus dominate the interpretation of antibody frequencies; HCs were blood donors presuming that they are the best surrogate that is available. ${ }^{17}$ In this study, 
1.703 HC samples were analyzed for antibodies against AMPAR1/2, AQP4, DNER, DPPX, GABAbR, GlyR, mGluR5, MOG, NMDAR/NR1, Caspr2, and Lgi1, however, restricted to serum. Zero positive samples were found for AQP4, DNER, GABAbR, and mGluR5. The most frequent antibody was targeting NMDAR/NR1 in 20 cases (1.2\%). The second largest $\mathrm{HC}$ cohort contained 274 samples, all negative for NMDAR/NR1. ${ }^{18}$ Cohorts exceeding $100 \mathrm{HC}$ samples were only available for 8 of 22 antibodies (figure e-1). Frequency determination of mGluR5 antibodies in HCs was restricted to a single study using CBA. ${ }^{17}$

The marked lack of systematic studies on antibody prevalence in HCs was less striking for disease controls. Three studies each described more than 1,000 samples, including psychiatric disorders and noninflammatory OND $(\mathrm{n}=2,533 ; 0 \%-1.34 \%$ positive for 10 NSAbs), ${ }^{17}$ people older than 60 years with unspecified diseases tested for muscle nAChR ( $\mathrm{n}=$ 2,000; $0.5 \%$ positive), ${ }^{19}$ and MS patients tested for AQP4 antibodies ( $\mathrm{n}=1,040 ; 0.3 \%$ positive, diagnosis in 2 of 3 was revised to NMOSD). ${ }^{20}$ In a recent study of 925 acutely ill psychiatric patients, $1.4 \%$ were NSAb-positive: 1 for AMPAR1/2, 5 for NMDAR/NR1, and 7 for Caspr2 antibodies. ${ }^{21} \mathrm{~A}$ subgroup of these patients was analyzed for DNER, DPPX, GlyR, mGluR5, and MOG antibodies, which were negative. ${ }^{22}$ All further studies contained markedly smaller cohorts with $\mathrm{n}=98$ for $\mathrm{PRG} 5^{23}$ to $\mathrm{n}=$ 741 tests for GlyR antibodies ${ }^{24}$ (mean 401 antibody tests per largest cohort), the positive cases ranged from $0 \%$ to $4.1 \%$ (mean $0.9 \%$ ) (table e- 1 ). Meaningful control groups were not always provided, such as patients with isolated lung cancer to compare with PRG5 antibody-positive cerebellar degeneration or patients with Hodgkin's lymphoma to compare with mGluR5 antibody-positive encephalitis.

DISCUSSION Focusing on the prevalence of the 22 most common antineuronal autoantibodies in healthy and disease controls, we identified 115,005 antibody tests performed between 1974 and 2016 . Of these, 96,280 samples were tested with the current standard method, which is the CBA for most NSAbs except RIA for VGKC and nAChR antibodies. Based on the comprehensive analysis, the frequency of NSAbs in HCs was very low with only $0.23 \%$ antibody-positive participants. Some NSAbs were not detected in a single $\mathrm{HC}$ subject, including AMPAR3, AQP4, DNER, GABAaR, GABAbR, mGluR5, nAChR (m), neurexin-3a, and PRG5 antibodies. For comparison with a well-known nonNSAb, antibodies against thyroid peroxidase were positive in $11.3 \%$ of 16,533 controls. ${ }^{25}$ The very low prevalence of NSAbs in HCs suggests high specificity, given that it clearly distinguishes patients with typical symptoms of NSAb-associated diseases in which $69.2 \%$ were antibody-positive in serum, certainly with broad differences among groups. Thus, NSAbs are well qualified as laboratory markers for antibody-mediated neuropsychiatric diseases. To determine sensitivity and specificity on clinical grounds, comparison with closely related disease groups is nonetheless required.

Prospective larger studies are needed and should include CSF samples. Analysis of the data brought to light that the knowledge on antibody prevalence in HCs is still scarce compared with the dramatic growth in NSAbmediated diseases. The main limitations in the field for interpreting the data are (1) the often very small sample number of controls in studies publishing a novel antibody and (2) the lack of CSF controls given that the CSF antibodies are often more diseaserelevant than serum.

The lack of CSF samples from controls makes the determination of specificity difficult in cases where CSF antibodies predominate, such as for NMDAR/ NR1, while it is less important when serum testing is generally sufficient, such as for MOG and AQP4. In fact, almost $95 \%$ of all reported control samples were serum probes. CSF samples were tested with the standard method from 2,788 controls, but for 8 antibodies, not a single control CSF has been tested.

Despite a relatively high number of studies that tested controls for the presence of NSAb $(n=309)$, only very few reported the systematic collection of samples, and most studies dealt with no or low numbers of HCs. Data from the few exceptions ${ }^{17,19-21}$ indicated that NSAbs are very infrequent in healthy and disease controls, ranging from $0 \%$ to $1.3 \%$ (mean $0.23 \%$ ). It is therefore possible that such small percentage of antibody-positive participants can easily be overlooked in studies with control numbers below 100 . Another possibility for the low rate of NSAb-positive cases in most studies might be susceptibility to selection bias or the lack of blinding to controls in the experimental design. On the contrary, it is possible that the true prevalence in HCs is even lower, given that most samples are from blood donors in which an extensive screen for comorbidities is not feasible.

Interpretation of a positive test result -6 things to consider in atypical clinical constellations. In clinical practice, the search for NSAb has become routine and broad laboratory panels occasionally return positive NSAbs in patients for which they were not initially suspected. To interpret the positive test result correctly, one has to take the following aspects into consideration.

First, although rare with the state-of-the-art CBAs, the test might represent a false-positive result. ${ }^{26}$ The 
validity can be markedly improved if 2 different assays are combined, e.g., the CBA plus determination of the characteristic anatomical binding to brain sections using immunofluorescence, which should be aimed to prevent unnecessary immunotherapy.

Second, the NSAb might be present in the circulation (true-positive), but not reaching its target in the brain or the peripheral nervous system. In that case, other factors might be relevant for pathogenic antibody effects ("second hit"), including the integrity of the blood-brain barrier or intrathecal antibody production.

Third, NSAb might hypothetically cause changes that can be measured by MRI or electrophysiology but are not obvious on clinical examination. Future studies will have to determine clinical relevance for neurologic patients, similar to other antibodymediated disorders such as celiac disease, where severe duodenal lesions frequently occur in asymptomatic patients. ${ }^{27}$

Fourth, the antibody could bind its target (and thus be positive in the diagnostic assay) but have no pathogenic effect.

Fifth, clinical relevance also relates to the knowledge on the pathogenicity of NSAbs. For many NSAbs, neuronal damage has been demonstrated in vitro and in vivo, ${ }^{2,5,28}$ including human monoclonal autoantibodies from CSF-derived plasma cells. ${ }^{3}$ In such cases, positive titers are likely risk factors for neuropsychiatric symptoms, similar to a drug or toxin level. ${ }^{3}$

Sixth, a positive NSAb in a patient not initially suspected to have an antibody-mediated disease can still be "true-positive" and represent the further expanding phenotypic spectrum seen in most subgroups.

Having these possibilities in mind, bedside interpretation of a positive antibody result must integrate antibody prevalence data, careful clinical evaluation of alternative diagnoses, predominance in CSF vs serum, experience of the laboratory performing the diagnostic assay, and consideration of antibody tests by a different method.

CONCLUSIONS NSAbs are rarely found in HCs, suggesting high disease specificity and supporting their pathogenic role and diagnostic usefulness in clinical routine. Conversely, positive titers in atypical patients might point to the still expanding phenotypic spectrum, in particular if confirmed in 2 independent diagnostic assays. Future prospective studies are needed and should include more CSF samples and data from HCs measured with blinded CBAs and different assay systems. Control groups in articles publishing novel autoantibodies should include at least $300-400$ participants, given that the mean prevalence of most NSAbs is very low (0.23\%) in HCs and wellselected disease controls. Increasing experimental evidence for antibody pathogenicity will facilitate the clinical decision for immunotherapy in NSAbpositive patients.

\section{AUTHOR CONTRIBUTIONS}

Katharina Lang: drafting/revising the manuscript; analysis or interpretation of data; and acquisition of data. Harald Prüss: drafting/revising the manuscript; study concept or design; analysis or interpretation of data; acquisition of data; statistical analysis; study supervision; and obtaining funding.

\section{STUDY FUNDING}

No targeted funding reported.

\section{DISCLOSURE}

The authors report no disclosures. Go to Neurology.org/nn for full disclosure forms.

Received April 1, 2017. Accepted in final form May 25, 2017.

\section{REFERENCES}

1. Dalmau J, Tuzun E, Wu HY, et al. Paraneoplastic anti$\mathrm{N}$-methyl-D-aspartate receptor encephalitis associated with ovarian teratoma. Ann Neurol 2007;61:25-36.

2. Hughes EG, Peng X, Gleichman AJ, et al. Cellular and synaptic mechanisms of anti-NMDA receptor encephalitis. J Neurosci 2010;30:5866-5875.

3. Kreye J, Wenke NK, Chayka M, et al. Human cerebrospinal fluid monoclonal N-methyl-D-aspartate receptor autoantibodies are sufficient for encephalitis pathogenesis. Brain 2016;139:2641-2652.

4. Planaguma J, Haselmann H, Mannara F, et al. Ephrin-B2 prevents N-Methyl-D-Aspartate receptor antibody effects on memory and neuroplasticity. Ann Neurol 2016;80: 388-400.

5. Planaguma J, Leypoldt F, Mannara F, et al. Human $\mathrm{N}$-methyl D-aspartate receptor antibodies alter memory and behaviour in mice. Brain 2015;138:94-109.

6. Lai M, Hughes EG, Peng X, et al. AMPA receptor antibodies in limbic encephalitis alter synaptic receptor location. Ann Neurol 2009;65:424-434.

7. Graus F, Titulaer MJ, Balu R, et al. A clinical approach to diagnosis of autoimmune encephalitis. Lancet Neurol 2016;15:391-404.

8. Almon RR, Andrew CG, Appel SH. Serum globulin in myasthenia gravis: inhibition of alpha-bungarotoxin binding to acetylcholine receptors. Science 1974; 4:55-57.

9. Stocker W, Saschenbrecker S, Rentzsch K, Komorowski L, Probst C. Autoantibody diagnostics in neurology using native and recombinant antigenic substrates [in German]. Nervenarzt 2013;84:471-476.

10. Lancaster E. The diagnosis and treatment of autoimmune encephalitis. J Clin Neurol 2016;12:1-13.

11. van Coevorden-Hameete MH, Titulaer M, Schreurs MWJ, Hoogenraad C. Detection and characterization of autoantibodies to neuronal cell-surface antigens in the central nervous system. Front Mol Neurosci 2016;9:37.

12. Lalive PH, Menge T, Delarasse C, et al. Antibodies to native myelin oligodendrocyte glycoprotein are serologic markers of early inflammation in multiple sclerosis. Proc Natl Acad Sci USA 2006;103:2280-2285. 
13. Fryer JP, Lennon VA, Pittock SJ, Jenkins SM, Wingerchuk $\mathrm{DM}$, McKeon A. AQP4 autoantibody assay performance in clinical laboratory service. Neurol Neuroimmunol Neuroinflamm 2014;1:e11. doi: 10.1212/NXI.0000000000000011.

14. van Sonderen A, Petit-Pedrol M, Dalmau J, Titulaer MJ. The value of LGI1, Caspr2 and voltage-gated potassium channel antibodies in encephalitis. Nat Rev Neurol 2017; 13:290-301.

15. Doss $\mathrm{S}$, Wandinger KP, Hyman $\mathrm{BT}$, et al. High prevalence of NMDA receptor IgA/IgM antibodies in different dementia types. Ann Clin Translational Neurol 2014;1: 822-832.

16. Karni A, Bakimer-Kleiner R, Abramsky O, Ben-Nun A. Elevated levels of antibody to myelin oligodendrocyte glycoprotein is not specific for patients with multiple sclerosis. Arch Neurol 1999;56:311-315.

17. Dahm L, Ott C, Steiner J, et al. Seroprevalence of autoantibodies against brain antigens in health and disease. Ann Neurol 2014;76:82-94.

18. Busse S, Busse M, Brix B, et al. Seroprevalence of N-methylD-aspartate glutamate receptor (NMDA-R) autoantibodies in aging subjects without neuropsychiatric disorders and in dementia patients. Eur Arch Psychiatry Clin Neurosci 2014; 264:545-550.

19. Vincent A, Clover L, Buckley C, Rothwell PM. Evidence of underdiagnosis of myasthenia gravis in older people. J Neurol Neurosurg Psychiatry 2003;74:1105-1108.

20. Pittock SJ, Lennon VA, Bakshi N, McKeon A, Barcellos LF. Seroprevalence of aquaporin-4-IgG in a Northern California population representative cohort of multiple sclerosis. JAMA Neurol 2014;71:1433-1436.
21. Schou M, Saether SG, Borowski K, et al. Prevalence of serum anti-neuronal autoantibodies in patients admitted to acute psychiatric care. Psychol Med 2016;46:3303-3313.

22. Sæther SG, Schou M, Stoecker W, et al. Onconeural antibodies in acute psychiatric inpatient care. J Neuropsychiatry Clin Neurosci 2017;29:74-76.

23. van Coevorden-Hameete MH, de Graaff E, Titulaer MJ, et al. Plasticity-related gene 5: a novel surface autoantigen in paraneoplastic cerebellar degeneration. Neurol Neuroimmunol Neuroinflamm 2015;2:e156. doi: 10.1212/NXI. 0000000000000156.

24. Carvajal-Gonzalez A, Leite MI, Waters P, et al. Glycine receptor antibodies in PERM and related syndromes: characteristics, clinical features and outcomes. Brain 2014;137: 2178-2192.

25. Hollowell JG, Staehling NW, Flanders WD, et al. Serum TSH, T4, and thyroid antibodies in the United States population (1988 to 1994): National Health and Nutrition Examination Survey (NHANES III). J Clin Endocrinol Metab 2002;87:489-499.

26. Gastaldi M, Thouin A, Franciotta D, Vincent A. Pitfalls in the detection of N-methyl-d-aspartatereceptor (NMDA-R) antibodies. Clin Biochem 2017; 50:354-355.

27. Trovato CM, Montuori M, Anania C, et al. Are ESPGHAN "biopsy-sparing" guidelines for celiac disease also suitable for asymptomatic patients? Am J Gastroenterol 2015;110:1485-1489.

28. Pettingill P, Kramer HB, Coebergh JA, Pettingill R, Waters P, Vincent A. Antibodies to GABAA receptor a1 and g2 subunits. Neurology 2015;84:1233-1241. 


\title{
Neurology \\ Neuroimmunology \& Neuroinflammation
}

\author{
Frequencies of neuronal autoantibodies in healthy controls: Estimation of disease \\ specificity \\ Katharina Lang and Harald Prüss \\ Neurol Neuroimmunol Neuroinflamm 2017;4; \\ DOI 10.1212/NXI.0000000000000386
}

This information is current as of July 18, 2017

\author{
Updated Information \& \\ Services \\ Supplementary Material \\ References \\ Citations \\ Subspecialty Collections \\ Permissions \& Licensing \\ Reprints
}

including high resolution figures, can be found at:

http://nn.neurology.org/content/4/5/e386.full.html

Supplementary material can be found at:

http://nn.neurology.org/content/suppl/2017/07/19/4.5.e386.DC1

This article cites 28 articles, 3 of which you can access for free at: http://nn.neurology.org/content/4/5/e386.full.html\#\#ref-list-1

This article has been cited by 6 HighWire-hosted articles: http://nn.neurology.org/content/4/5/e386.full.html\#\#otherarticles

This article, along with others on similar topics, appears in the following collection(s):

Cerebrospinal Fluid

http://nn.neurology.org//cgi/collection/cerebrospinal_fluid

Information about reproducing this article in parts (figures,tables) or in its entirety can be found online at:

http://nn.neurology.org/misc/about.xhtml\#permissions

Information about ordering reprints can be found online:

http://nn.neurology.org/misc/addir.xhtml\#reprintsus

Neurol Neuroimmunol Neuroinflamm is an official journal of the American Academy of Neurology.

Published since April 2014, it is an open-access, online-only, continuous publication journal. Copyright

Copyright $\odot 2017$ The Author(s). Published by Wolters Kluwer Health, Inc. on behalf of the American

Academy of Neurology. All rights reserved. Online ISSN: 2332-7812.

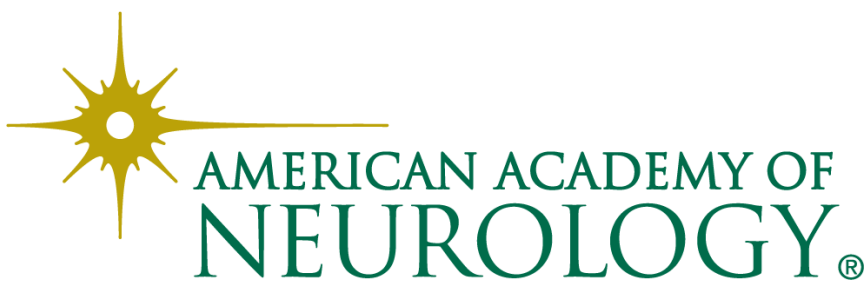

